\title{
Antibiotic resistance pattern of the strains isolated in urinary tract infections in the last semester in the military hospital
}

\author{
Simona Costin*, Michaela Oana, Mihai Feier, Asiza Olteanu
}

From The 9th Edition of the Scientific Days of the National Institute for Infectious Diseases Prof Dr Matei Bals Bucharest, Romania. 23-25 October 2013

\section{Background}

In the last years the antibiotic resistance is increasing, and self-medication is no longer the only reason. The study was designed to compare community urinary tract infections (UTI) and hospitalized patients' UTI.

\section{Method}

We performed a retrospective study of the resistance pattern of the main strains isolated from the hospitalized patients admitted to the Emergency Military Hospital in Cluj-Napoca between 01 January - 30 June 2013, and from the urine sample of the ambulatory patients, during the same period. For antibiotic susceptibility we used the semiautomatic VITEK 2 system and the diffusimetric method. We studied demographic characteristics, in correlation with microbiological data.

\section{Results}

For the hospitalized patients: from 317 samples, 209 were positive, in which we isolated $E$ coli $=79 \%$, Enterobacter $=9.5 \%$, Proteus $\mathrm{spp}=5 \%$, Klebsiella $=5 \%$, Enterococcus spp, Serratia spp, Staphylococcus $=1.5 \%$. The $E$ coli sensitivity to antimicrobial drugs was found to be as follows: ampicillin $=30 \%$, cefepime $=50 \%$, norfloxacin $=62 \%$, ofloxacin, ciprofloxacin $=68 \%$, biseptol $=63 \%$, amoxicillin+clavulanic acid $=70 \%$, ceftazidime $=85 \%$, amikacin $=98 \%$, nitrofurantoin and carbapenem $=100 \%$.

For the ambulatory patients: from 605 urinary samples, 318 were positive, in which we isolated: $E$ coli $=72.5 \%$, Enterobacter $=12.5 \%$, Proteus $=10 \%$-mainly nosocomial, after prostatectomy or urinary catheter, Klebsiella, Enterococcus, Citrobacter $=5 \%$.

\footnotetext{
* Correspondence: sincostin@yahoo.com

"Dr. Constantin Papilian" Emergency Military Hospital, Cluj-Napoca, Romania
}

\section{Conclusion}

Urine culture is a routine microbiological investigation, even when not indicated. The treatment of asymptomatic bacteriuria is a controversial issue, especially for ambulatory patients. E coli remains the most common strain isolated in urine cultures, and the antimicrobial stewardship is necessary.

Published: 16 December 2013

doi:10.1186/1471-2334-13-S1-P33

Cite this article as: Costin et al:: Antibiotic resistance pattern of the strains isolated in urinary tract infections in the last semester in the military hospital. BMC Infectious Diseases 2013 13(Suppl 1):P33.
Submit your next manuscript to BioMed Central and take full advantage of:

- Convenient online submission

- Thorough peer review

- No space constraints or color figure charges

- Immediate publication on acceptance

- Inclusion in PubMed, CAS, Scopus and Google Scholar

- Research which is freely available for redistribution
C Biomed Central 